\title{
Optimization of Hydraulic Horsepower to Predict the Rate of Penetration
}

\author{
Herianto \\ Petroleum Engineering Department, Faculty of Technology and Mineral, UPN “Veteran” Yogyakarta, D. I. Yogyakarta, Indonesia \\ Email address: \\ herianto_upn_ina@yahoo.com, herianto.topan@upnyk.ac.id

\section{To cite this article:} \\ Herianto. Optimization of Hydraulic Horsepower to Predict the Rate of Penetration. American Journal of Physics and Applications. \\ Vol. 6, No. 3, 2018, pp. 63-75. doi: 10.11648/j.ajpa.20180603.11
}

Received: February 22, 2018; Accepted: March 19, 2018; Published: May 10, 2018

\begin{abstract}
The rate of penetration has an important role in the success of a drilling operation, this is because if the rate of penetration is not optimum will have an impact on the cost incurred. Some factors that influence the rate of penetration are the weight on bit, rotation per minute and horsepower. Based on the analysis obtained WOB and RPM values are optimum so that optimization is done on horsepower. In this case study the well that will be analyzed is vertical well so that bit's hydraulic optimization is performed using Bit Hydraulic Horse Power (BHHP) method by adjusting the nozzle size and circulation rate, this method will be optimum if BHHP / HPs ratio is $65 \%$. Evaluation on trajectory $12 \%$ well "SGT-01" field "Tranusa", obtained bit's hydraulics on the actual conditions at $2657.48 \mathrm{ft}-2723.10 \mathrm{ft}$ depth interval obtained Bit Hydraulic Horse Power (BHHP) of $232.67 \mathrm{hp}$, Horse Power Surface (HPs) $499.82 \mathrm{hp}$, Horse Power per Square Inches (HSI) of $1.67 \mathrm{hp} / \mathrm{in}^{2}$ and percentage (BHHP / HPs) of $46.55 \%(<65 \%)$ indicating less optimum then optimized hydraulic bit circulation rate optimized to 710 gpm with Horsepower Hydraulic Horse Power (HPH) of $936.47 \mathrm{hp}$, Horse Power per Square Inches (HSI) of $5.4 \mathrm{hp} / \mathrm{in}^{2}$ and percentage (BHHP / HPs) of $65 \%$ (already optimum). The final result of the evaluation and optimization of bit hydraulics and the removal of cutting is predicted to increase ROP from $46 \mathrm{fph}$ to $125.66 \mathrm{fph}$.
\end{abstract}

Keywords: Hydraulic Horsepower, Drilling Optimization, ROP Prediction

\section{Introduction}

Increasing the complexity of drilling operations has increased some of the issues that make drilling cost considerations [1]. There are several parameters that affect drilling performance and if not done properly or optimum, the company will lose money because it does not save the cost of drilling exactly adds to the cost issued. Some of these parameters, among others, weight on bit (WOB), rotation per minute (RPM), flow rate, bit hydraulics and bit type are the most important drilling parameters affecting the rate of penetration (ROP) and the drilling economy. The rate of penetration is directly proportional to drilling parameters such as WOB, RPM, and Horsepower making it a very important methodology in considering the previous drilling data and making optimum drill prediction [2].

It has long been known that drilling fluid properties can dramatically impact drilling rate. This fact was established early in the drilling literature, and confirmed by numerous laboratory studies. Several early studies focused directly on mud properties, clearly demonstrating the effect of kinematic viscosity at bit conditions on drilling rate. In laboratory conditions, penetration rates can be affected by as much as a factor of three by aitering fluid viscosity. It can be concluded from the early literature that drilling rate is not directly dependent on the type or amount of solids in the fluid, but on the impact of those solid on fluid properties, particularly on the viscosity of the fluid as it flows through bit nozzles. This conclusion indicates that drilling rates should be directly correlative to fluid properties which reflect the viscosity of the fluid at bit shear rate conditions, such as the plastic viscosity. Secondary fluid properties reflecting solids content in the fluid should also provide a means of correlating to rate of penetration, as the solids will impact the viscosity of the fluid [3].

The factors which affect rate of penetration are exceedingly numerous and perhaps important variables exist which are unrecognized up to this time. A rigorous analysis of drilling 
rate is complicated by difficulty of completely isolating the variable under study. For example, interpretation of field data may involve uncertainties due to the possibility of undetected changes in rock properties. Studies of drilling fluid effects are always plagued by difficulty of preparing two muds having all properties identical except one which is under observation. While it is generally desirable to increase penetration rate, such gains must not be made at the expense of overcompensating, detrimental effects. The fastest on-bottom drilling rate does not necessarily result in the lowest cost per foot of drilled hole. Other factors such as accelerated bit wear, equipment failure, etc., may raise cost [4]. Optimization of drilling hydraulics can be obtained by increasing the drilling rate [5].

In this paper, Hydraulic horsepower has an important role in drilling operations, the timing of drilling also greatly affects the costs incurred. The size of the horsepower is directly proportional to the rate of penetration (ROP) where the greater the horsepower the faster the rate of penetration. Basically, the parameters associated with the rate of penetration in the drilling hydraulics include weight on bits, rotation per minute and horsepower. Optimization of hydraulics needs to be done to obtain optimum drilling results if the rapid penetration rate will be obtained a good drill cleaning effect, good cutting removal, no regrinding and no bit balling.

\section{Method}

The steps were taken in hydraulic optimization and cutting removal are as follows:

1. Calculating actual bit hydraulics.

2. Calculating the actual lifting of the cutting hydraulics.

3. Calculate the maximum pressure conditions.

4. Calculating Qmin.

5. Calculating Qmax.

6. Bit hydraulics optimization.

7. Optimization of hydraulic removal of cutting.

\subsection{Drilling Hydraulic and Cutting Lifting Optimization}

Data processing performed on drilling hydraulics includes calculation of pressure loss on the bit, percentage of pressure loss on the bit and loss of surface power. Calculation of Pressure Loss on Flow System Except on Bit (Pp) is done by calculating the average velocity of mud and critical velocity in both the circuit and in the annulus.

\subsubsection{Calculation of Pressure Loss on Flow System Except on Bit}

Loss of pressure on the flow system except on the bit is influenced by the flow patterns occurring within ranges and annulus, the first step to determine the flow pattern by calculating the average velocity of the mud and the critical velocity of the mud, if $\mathrm{V}>\mathrm{Vc}$ then the flow pattern is turbulent otherwise $\mathrm{V}<\mathrm{Vc}$ then the flow pattern is laminar (Rabia, H., 1985).

\subsubsection{Calculation of Average Flow Rate of Mud (V)}

The average velocity of mud flow (V) using the equation:

$$
\mathrm{V}=\frac{\text { Qdata }}{2.45\left(\mathrm{ID}^{2}\right)}
$$

Where:

Q data $=$ Data's Rate, gpm.

ID = Inner Diameter, inch.

The average velocity of mud flow (Van) using the equation:

$$
\operatorname{VanDP}=\frac{\text { Qdata }}{2.45\left(\mathrm{DH}^{2}-\mathrm{OD}^{2}\right)}
$$

Where:

Q data $=$ Data's Rate, gpm.

$\mathrm{OD}=$ Outer Diameter, inch .

$\mathrm{DH}=$ Hole Diameter, inch.

\subsubsection{Critical Velocity Calculation (VC)}

Critical Velocity (VC) using the equation:

$$
V c=\frac{1.078}{\rho m I D}\left(P V+\sqrt{P V^{2}+12.34(I D)^{2} Y P \rho m}\right)
$$

Where:

$\mathrm{PV}=$ Plastic viscosity, $\mathrm{cp}$.

ID = Inner Diameter, inch.

YP $=$ Yield point, $100 \mathrm{lb} / \mathrm{ft}$.

$\rho \mathrm{m}=$ Density, ppg.

Critical velocity in annulus (VCan) using the equation:

$$
V c=\frac{1.078}{\rho m(H D-O D)}\left(P V+\sqrt{P V^{2}+9.256(H D-O D)^{2} Y P \rho m}\right)
$$

Where:

$\mathrm{PV}=$ Plastic viscosity, $\mathrm{cp}$.

OD $=$ Outer Diameter, inch.

$\mathrm{DH}=$ Hole Diameter, inch .

$\mathrm{YP}=$ Yield point, $100 \mathrm{lb} / \mathrm{ft}$.

$\rho \mathrm{m}=$ Density, ppg.

After determining the flow patterns that occur in the string and in the next annulus calculate the loss of pressure on the surface connection (PSC). Total loss of pressure on the system is usually expressed in the equivalent of the discharge line consisting of 4 categories, including flow line, stand pipe, swivel, and Kelly. Based on the type of surface connection used in the drilling operation can be seen the price of constant pressure loss pressure on the surface. As shown in Table 1 and Table 2 below. 
Table 1. Surface Connection Type (B. C. Craft, et. Al., 1962).

\begin{tabular}{lllllllll}
\hline \multirow{3}{*}{ Surface eq. type } & Stand pipe & \multicolumn{3}{l}{ Rotary hose } & \multicolumn{2}{c}{ Swivel } & \multicolumn{2}{c}{ kelly } \\
\cline { 2 - 9 } & Length & ID & Length & ID & Length & ID & length & ID \\
\cline { 2 - 9 } & (ft) & (in) & (ft) & (in) & (ft) & (in) & (ft) & (in) \\
\hline 1 & 40 & 3 & 40 & 2 & 4 & 2 & 40 & 2.25 \\
2 & 40 & 3.5 & 55 & 2.5 & 5 & 2.5 & 40 & 3.25 \\
3 & 45 & 4 & 55 & 3 & 5 & 2.5 & 40 & 3.25 \\
4 & 45 & 4 & 55 & 3 & 6 & 3 & 40 & 4 \\
\hline
\end{tabular}

Table 2. E Constanta Value Based On Surface Connection Type (B. C. Craft, et. Al., 1962).

\begin{tabular}{lll}
\hline \multirow{2}{*}{ surface eq. type } & \multicolumn{2}{l}{ Value of E } \\
\cline { 2 - 3 } & Imperial units & Metric units \\
\hline 1 & $2.5 \times 10^{-4}$ & $8.8 \times 10^{-6}$ \\
2 & $9.6 \times 10^{-5}$ & $3.3 \times 10^{-6}$ \\
3 & $5.3 \times 10^{-5}$ & $1.3 \times 10^{-6}$ \\
4 & $4.2 \times 10^{-5}$ & $1.4 \times 10^{-6}$ \\
\hline
\end{tabular}

The amount of pressure loss on the surface connection is calculated by the equation:

$$
P S C=\mathrm{E} \rho^{0.8} \mathrm{Q}^{1.8} \mathrm{PV}^{0.2}
$$

Where:

$\mathrm{P}_{\mathrm{SC}}=$ Pressure Loss in Surface Connection, psi.

$\mathrm{E}=$ Surface Connection Cnstanta Type

$\mathrm{p}=$ Mud Density, lb/gal.

$\mathrm{Q}=$ Mud Rate, gpm

$\mathrm{PV}=$ Plastic viscosity, $\mathrm{cp}$

The amount of pressure loss inside the pipe can be calculated based on the flow pattern (B. C. Craft, et. Al., 1962).

The flow is Laminar, then it is calculated by using the equation:

$$
P=\frac{P V L V}{1500 d i^{2}}+\frac{Y P L}{225 d i^{2}}
$$

Where:

$\mathrm{PV}=$ Plastic viscosity, $\mathrm{cp}$.

ID = Inner Diameter, inch.

$\mathrm{L}=$ Length, $\mathrm{ft}$.

$\mathrm{YP}=$ Yield point, $100 \mathrm{lb} / \mathrm{ft}$.

The flow is Turbulent, then it is calculated by using the equation:

$$
P=\frac{f \times L \times \rho m \times V^{2}}{25.8 \times I d}
$$

Where:

$$
\mathrm{Pp}=\mathrm{Psc}+\mathrm{PDP}+\mathrm{PDC}+\mathrm{PHWDP}+\mathrm{PMWD}+\mathrm{PanDP}+\mathrm{PanDC}+\mathrm{PanHWDP}+\mathrm{PanMWD}
$$

\subsubsection{Calculation of Actual Hydraulics Bit Using BHHP Method}

The basic principle of this method assumes that the greater the power delivered by the fluid to the rock will be the greater the cleaning effect so that the method seeks to optimize the horsepower used on the surface of the pump. The BHHP concept assumes that hydraulic optimization is achieved when the lost horsepower on the bit is $65 \%$ of its power. The BHHP $\mathrm{f}=$ friction.

ID = Inner Diameter, inch.

$\mathrm{L}=$ Length, $\mathrm{ft}$.

$\mathrm{V}=$ Velocity, fps.

$\rho \mathrm{m}=$ Density, ppg.

The value $\mathrm{f}$ is obtained by calculating the Reynold Number then determined by looking at the fanning friction graph (B. C. Craft, et. al. 1962).

$$
\text { Nre }=\frac{928 \rho v d}{\mu}
$$

Where:

$\mathrm{P}=$ Fluid Density, ppg

$\mathrm{V}=$ Velocity, $\mathrm{fps}$

$\mathrm{d}=$ Pipe Diameter, in

$\mu=$ effective viscosity, $\mathrm{cp}$.

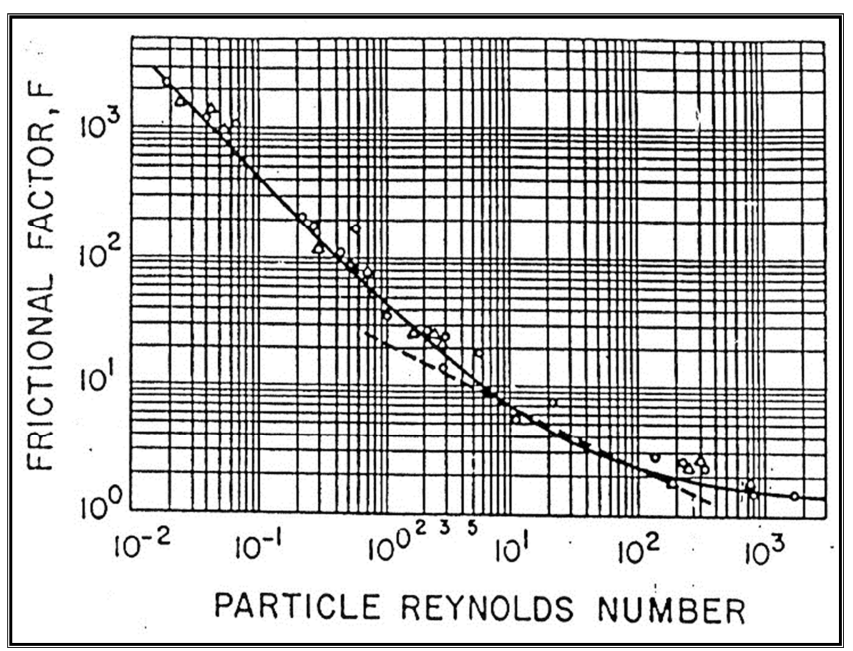

Figure 1. Relation of reynold number with fanning friction (Rabia, 2002)

After calculating the loss of pressure then calculates the total pressure loss (parasitic pressure loss) on the flow system by using the equation:

concept is suitable for drilling on vertical wells and rock types with consideration of gravity (Rabia, H., 1985).

$$
\begin{gathered}
\mathrm{BHHP}=\frac{\text { Qdata } P b}{1714} \\
\mathrm{HPS}=\frac{\text { Qdata Pdata }}{1714}
\end{gathered}
$$

Where:

$\mathrm{Q}=$ Rate, gpm 
$\mathrm{Pb}=$ Pressure Loss on bit, psi

Calculation of how much power on the bit used to clean the bottom of the wellbore during drilling activity, namely by comparing BHHP price with the large power pump on the surface (HPs) (Rabia, H., 1985).

$$
=\frac{B H H P}{H P S} \times 100 \%
$$

Determining the Horse Power Per Square Inch (HSI) value:

$$
\text { HSI }=\frac{\text { BHHP }}{\frac{\pi}{4} \times(D h)^{2}}
$$

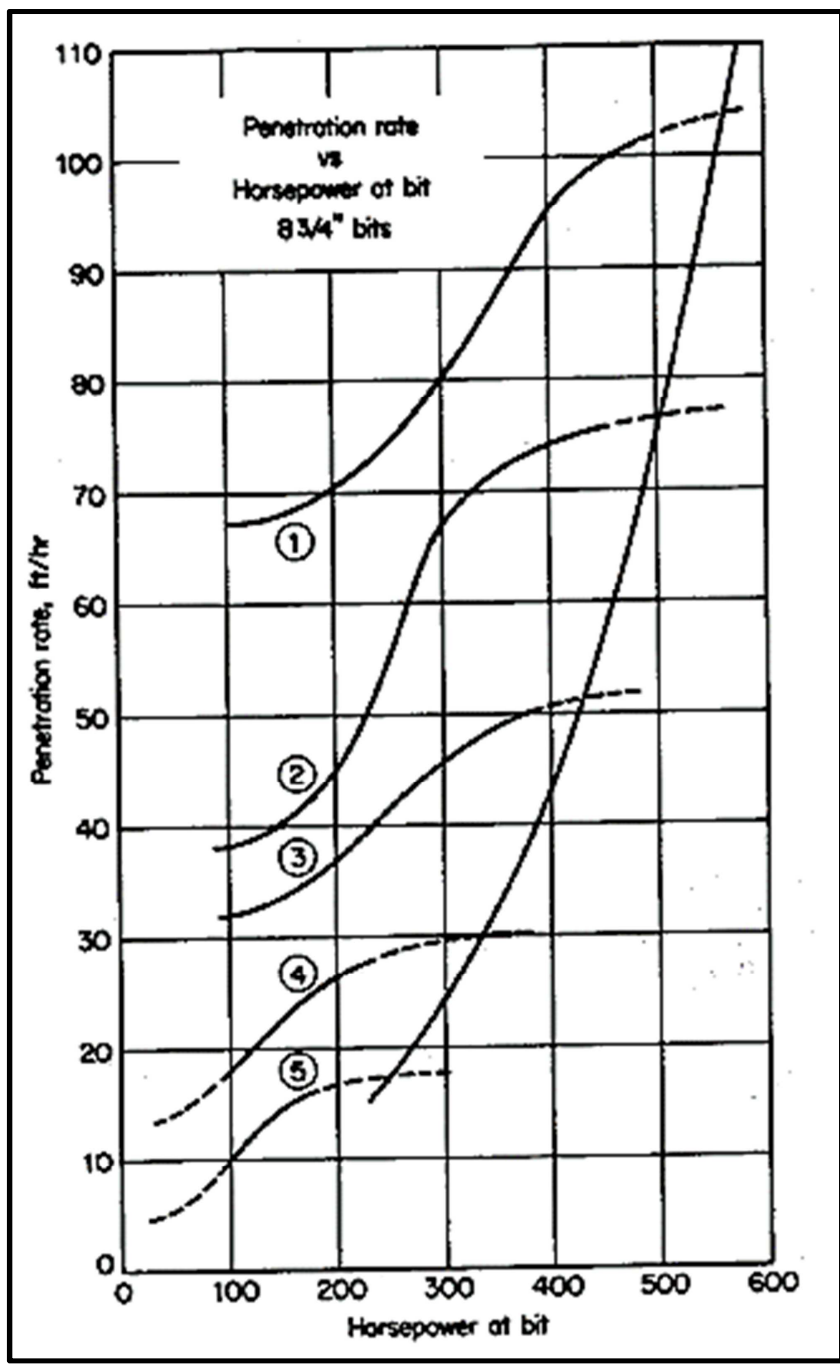

Figure 2. Relation of ROP and Horsepower. (Carl Gatlin, 1960).

Figure 2 shows the curve relationship between horsepower and rate of penetration. In low horsepower conditions, the cleaning effect of small holes and small ROP. ROP price increase can be known by increasing horsepower. But at some point, the sharp increase in speed is achieved from the relatively small speed (Carl Gatlin, 1960).

\subsubsection{Calculation of Actual Cutting Hydraulics}

Based on the physical properties of the drilling mud used, the power law index is calculated by the equation:

$$
n=3.32 \log \left(\frac{2 P V+Y P}{P V+Y P}\right)
$$

Where:

$\mathrm{PV}=$ Plastic Viscosity, cp.

$\mathrm{YP}=$ Yield point, $100 \mathrm{lb} / \mathrm{ft}$.

The Consistency Index is calculated using the equation:

$$
\mathrm{K}=\frac{(\mathrm{PV}+\mathrm{YP})}{511^{\mathrm{n}}}
$$

Where:

$\mathrm{PV}=$ Plastic Viscosity, cp.

$\mathrm{n}=$ power law index

$\mathrm{YP}=$ Yield point, $1001 \mathrm{~b} / \mathrm{ft}$.

Based on the mud flow rate, the diameter of the hole and the drill pipe, the velocity of the mud flow in the annulus can be calculated by the equation:

$$
\mathrm{Va}=\frac{\mathrm{Q}}{2.45\left(\mathrm{Dh}^{2}-\mathrm{OD}^{2}\right)}
$$

Where:

$\mathrm{Q}=$ Rate, gpm.

OD $=$ Outer Diameter, inch.

$\mathrm{DH}=$ Hole Diameter, inch.

Calculate the critical velocity of mud $(\mathrm{Vc})$ for power-law fluid by equation:

$\mathrm{Vc}=\left[\frac{3.878 .\left(10^{4}\right) \mathrm{K}}{510 . \rho}\right]^{\frac{1}{2-\mathrm{n}}}\left[\left(\frac{2.4}{\mathrm{dh}-\mathrm{od}}\right)\left(\frac{2 \mathrm{n}+1}{3 \mathrm{n}}\right)\right]^{\frac{\mathrm{n}}{2-\mathrm{n}}}$

Where:

$\mathrm{K}=$ Indeks konsistensi.

$\mathrm{n}=$ Indeks power law.

$\rho=$ Density, ppg.

OD $=$ Outer Diameter, inch.

$\mathrm{DH}=$ Hole Diameter, inch.

The apparent viscosity is calculated using the equation:

$$
\mu \mathrm{an}=\frac{\mathrm{K}}{144}\left(\frac{\mathrm{DH}-\mathrm{OD}}{\operatorname{Van}}\right)^{1-\mathrm{n}}\left(\frac{2+1 / \mathrm{n}}{0.0208}\right)^{\mathrm{n}}
$$

Where:

$\mathrm{K}=$ Consistency Index.

$\mathrm{n}=$ Indeks power law.

Van $=$ Annulus Velocity, fps.

OD $=$ Outer Diameter, inch

$\mathrm{DH}=$ Hole Diameter, inch.

The vertical slip speed of cutting for the laminar flow can be calculated using the equation:

$$
\mathrm{Vsv}=\frac{82.87 \mathrm{Ds}^{2}(\rho \mathrm{s}-\rho \mathrm{m})}{\mu \mathrm{an}}
$$


Where:

$\rho \mathrm{s}=$ Density cutting, ppg.

Ds $=$ cutting Diameter, inch.

$\rho \mathrm{m}=$ mud Density, ppg.

$\mu \mathrm{an}=$ apparent Viskosity, $\mathrm{cp}$.

Slip cutting speed after correction of inclination angle, density, and RPM can be calculated using equation:

$$
\mathrm{Vs}=\left[1+\frac{\theta(600-\mathrm{Rpm})(3+\rho \mathrm{m})}{202500}\right] \mathrm{Vsv}
$$

Where:

$\mathrm{Rpm}=$ Rotation per minute.

$\rho \mathrm{m}=$ mud Density, ppg.

Vsv $=$ vertical slip velocity, fps.

Cutting Transport Ratio (Ft) can be calculated using equation:

$$
\Phi_{\tau}=\frac{\mathrm{v}_{\alpha}-\mathrm{v}_{\mathrm{S}}}{\mathrm{v}_{\alpha}}
$$

Where:

$\mathrm{Va}=$ mud velocity, fps.

$\mathrm{Vs}=$ mud slip velocity, fps.

Cutting Concentration (Ca) can be calculated using equation:

$$
\mathrm{Ca}=\frac{(\mathrm{ROP}) \mathrm{D}^{2}}{14.7 \mathrm{FtQ}} 100 \%
$$

Where:

$\mathrm{ROP}=$ Rate Of Penetration, $\mathrm{ft} / \mathrm{hr}$.

$\mathrm{D}=$ Diameter Hole, inch.

$\mathrm{Ft}=$ Cutting transport ratio, $\%$.

$\mathrm{Q}=$ Rate, gpm.

Particle Bed Index (PBI) can be calculated by first looking for the value of Vsa and Vsr equations:

$$
\begin{aligned}
\mathrm{Vsa} & =\mathrm{Vs} \cos \varnothing \\
\mathrm{Vsr} & =\mathrm{Vs} \sin \varnothing
\end{aligned}
$$

Where:

Vs $=$ slip velocity, fps.

Cutting will settle within a certain time which can be calculated using the equation:

$$
\mathrm{T}_{\mathrm{S}}=\frac{\frac{1}{12}(\mathrm{Dh}-\mathrm{OD})}{\mathrm{v}_{\mathrm{Sr}}}
$$

Where:

DH $=$ Hole Diameter, inch.

OD $=$ Outer Diameter, inch.

$\mathrm{Vsr}=$ radial slip velocity, fps.

The distance taken by cutting before settling can be calculated using the equation:

$$
\mathrm{L}_{\mathrm{cDP}}=\left(\mathrm{v}_{\mathrm{a}}-\mathrm{v}_{\mathrm{sa}}\right) \mathrm{T}_{\mathrm{s}}
$$

Where:

$\mathrm{Va}=$ mud velocity, fps.

$\mathrm{Vsa}=$ direct mud velocity, fps.

Particle Bed Index (PBI ) can be calculated using the equation:

$$
\mathrm{PBI}=\frac{\frac{1}{12}(\mathrm{Dh}-\mathrm{OD})\left(\mathrm{v}_{\mathrm{a}}-\mathrm{v}_{\mathrm{Sa}}\right)}{\mathrm{L}_{\mathrm{c}} \mathrm{v}_{\mathrm{Sr}}}
$$

Where:

DH $=$ Hole Diameter, inch.

OD $=$ Outer Diameter, inch.

$\mathrm{Va}=$ mud Velocity, fps.

$\mathrm{Vsa}=$ direct mud Velocity, fps

\subsection{Calculation of Pump Flow Rate and Pump Pressure}

\subsubsection{Calculating Qmax Pump}

Calculation of the maximum pump flow rate of the combined three pumps, namely the duplex pumps arranged in parallel as follows:

Calculate maximum pump power (HPmax):

HPmax $=$ HP pump max $\times$ Eff pump $\times$ Number of Pumps

Calculates maximum pump flow rate (Qmax):

$$
\text { Qmax }=\text { Number of Pumps } \times \text { Qmax pump } \times \text { Eff pump }
$$

Calculate pump maximum pressure (Pmax) using the equation:

$$
\text { Pmaks }=\frac{\text { HPmaks } \times 1714}{\text { Qmaks }}
$$

\subsubsection{Qmin with the Annular Velocity Minimum Concept}

The calculation of Qmin using the Minimum Annular Velocity method begins with determining the velocity slip cutting (Herianto and Subiatmono, 2001). Velocity slip is the minimum velocity where cutting can begin to rise or in practice is a reduction in velocity mud and velocity falling from the cutting expressed by the equation:

$$
\mathrm{Vs}=\mathrm{Vmin}-\mathrm{Vcut}
$$

Where:

$\mathrm{Vs}=$ slip Velocity, $\mathrm{ft} / \mathrm{s}$.

$\mathrm{Vmin}=$ minimum Velocity, ft/s.

Vcut $=$ cutting Velocity, ft/s.

Vcut equation:

$$
V c u t=\frac{R O P}{\left[1-\left(\frac{d_{o d p}}{d_{h}}\right)^{2}\right] 72}
$$

Where:

$d_{o d p}=$ Pipe Outer Diameter (Dp atau Dc), in. 
$d_{h}=$ Borehole Diameter, in.

$\mathrm{ROP}=$ Rate of penetration, $\mathrm{ft} / \mathrm{hr}$.

Then corrected the Vmin Equation on all parameters (correction of inclination, correction of density, correction to $\mathrm{Rpm}$ ), for vertical wells, directional, and horizontal. This equation can be used for inclination angle $0^{\circ}$ to $90^{\circ}$. The equation is as follows:

$$
\mathrm{Vmin}=\mathrm{Vcut}+\mathrm{Vs}
$$

Where:

$\mathrm{Vs}=\operatorname{slip}$ Velocity, $\mathrm{ft} / \mathrm{s}$.

$\mathrm{Vmin}=$ minimum Velocity, $\mathrm{ft} / \mathrm{s}$.

Vcut = cutting Velocity, $\mathrm{ft} / \mathrm{s}$.

Then the equation becomes:

$$
V \min =V c u t+\left(1+C_{i} * C_{m w} * C_{R p m}\right) V s v
$$

then for:

$$
\begin{gathered}
\theta \leq 45 \\
V \min =V c u t+\left[1+\frac{\theta(600-R p m)(3+\rho m)}{202500}\right] V s v \\
\theta \geq 45 \\
V \min =V c u t+\left[1+\frac{(600-R p m)(3+\rho m)}{4500}\right] V s v
\end{gathered}
$$

Where:

Vcut $=$ cutting Velocity, ft/s.

$\mathrm{Vsv}=$ vertical slip Velocity $\mathrm{ft} / \mathrm{s}$.

$\mathrm{RPM}=$ Rotation per minute

$\rho \mathrm{m}=$ mud Density, ppg.

$\theta=$ incline degree $\left(^{\circ}\right)$.

Velocity cutting is a function of ROP, $d_{\text {odp }}, d_{h}$. The Vcut equation is as follows:

$$
\text { Vcut }=\frac{R O P}{36\left[1-\left(\frac{d_{\text {odp }}}{d_{h}}\right)^{2}\right] \text { Cconc }}
$$

Where:

$d_{o d p}=$ Pipe Outer Diameter (Dp atau Dc), in.

$d_{h}=$ BoreHole Diameter, in .

Cconc $=$ cutting concentration, $\%$.

$\mathrm{ROP}=$ Rate of penetration, $\mathrm{ft} / \mathrm{hr}$.

Equation of cutting concentration:

$$
\mathrm{C}_{\text {conc }}=0.01778 \mathrm{ROP}+0.505
$$

Then the mud flow rate in the annulus can be calculated by the equation:

$$
\mathrm{Q}_{\min }=\mathrm{K} \times \mathrm{A}_{\text {annulus }} \times \mathrm{Vmin}
$$

$$
Q \min =3.1172 \times \frac{1}{4} \pi\left(d_{h}^{2}-d_{o d p}^{2}\right) x V \min
$$

Where:

$\mathrm{Qmin}=$ minimum rate, gpm.

$\mathrm{K}=$ conversion constanta.

$\mathrm{Vmin}=$ minimum Velocity, $\mathrm{ft} / \mathrm{s}$.

$d_{o d p}=$ Pipe Outer Diameter (Dp atau Dc), in.

$d_{h}=$ Borehole Diameter, in.

Calculate the total optimum nozzle area with the equation:

$$
x=\left[\frac{\mathrm{Pm} \cdot \mathrm{Q}^{2}}{10.858 \cdot P b}\right]^{\frac{1}{2}}
$$

Where:

$\mathrm{Q}=$ Rate, gpm.

$\mathrm{Pm}=$ maximum pump pressure, psi.

$\mathrm{Pb}=$ pressure loss, psi.

$\mathrm{z}=$ power factor

Determine nozzle combination from nozzle area by equation:

$$
A n=\frac{1}{4} \pi\left(\frac{x}{32}\right)^{2} x \text { Total Nozzle }
$$

Where:

$\mathrm{x}=$ nozzle area, inch $^{2}$

\section{Result}

WELL DATA:

Depth $=2657.48-2723.10 \mathrm{ft}$.

Hole Diameter $=12.25$ in.

Diameter OD DP $=5$ in.

Pump rate $=660$ gpm.

Plastic Viscosity $=23 \mathrm{cp}$.

Yield Point $=30 \mathrm{lb} / 100 \mathrm{ft}$.

Density mud $=11.50 \mathrm{ppg}$.

Density of drill powder $=19.39 \mathrm{ppg}$.

Diameter of drill powder $=0.16$ in.

The rate of penetration $=46 \mathrm{fph}$.

Inclination $=0.30^{\circ}$

\subsection{Calculation of Actual Hydraulics}

\subsubsection{Calculation of Pressure Loss on Flow System Except on Bit (Pp)}

The calculation of pressure loss is done by calculating the velocity of the mud flow in the circuit and in the annulus. An example calculation is done on $12 \frac{1 / 4}{4}$ trajectory Wells "SGT-01" with Depth Interval $2657.48 \mathrm{ft}-2723.10 \mathrm{ft}$ :

Average Velocity Calculation of Mud Flow (V)

- Velocity of average mud flow in drill pipe (VDP) using Equation (1):

$$
\mathrm{VDP}=\frac{\text { Qdata }}{2.45\left(\mathrm{ID}^{2}\right)}
$$




$$
\begin{gathered}
\mathrm{VDP}=\frac{659}{2.45\left(4.28^{2}\right)} \\
\mathrm{VDP}=14.71 \mathrm{fps}
\end{gathered}
$$

- Velocity of average mud flow in annulus drill pipe (Van DP) using Equation (2):

$$
\text { VanDP }=\frac{\text { Qdata }}{2.45\left(\mathrm{DH}^{2}-\mathrm{OD}^{2}\right)}
$$

$$
\begin{gathered}
\operatorname{VanDP}=\frac{660}{2.45\left(12.25^{2}-5^{2}\right)} \\
\operatorname{VanDP}=2.15 \mathrm{fps}
\end{gathered}
$$

The calculation result of mud flow average in Wells "SGT-01" in the example of Depth Interval $2657.48 \mathrm{ft}$ $2723.10 \mathrm{ft}$ (trajectory $12 \frac{1}{4}$ ") can be seen in Table 3.

Table 3. Results Calculation of Velocity of Mud Flow in Example of Depth Interval $2657.48 \mathrm{ft}-2723.10 \mathrm{ft}$ (trajectory 12 1/4') Wells "SGT-01".

\begin{tabular}{llll}
\hline Mud Flow Velocity in String & & & MWD \\
\hline Dp & Dc & HWDP & fps \\
\hline Fps & Fps & fps & 29.89 \\
\hline 14.71 & 29.89 & 32.54 & \\
\hline & & & MWD \\
\hline Mud Flow Velocity in Annulus & & & Fps \\
\hline DP & DC & HWDP & 3.13 \\
\hline Fps & fps & fps & \\
\hline 2.15 & 3.13 & 2.15 & \\
\hline
\end{tabular}

Calculation of Critical Velocity (VC)

- Velocity critical on drill pipe (VCDP) with Equation

(3):

$$
V c=\frac{1.078}{\rho m I D}\left(P V+\sqrt{P V^{2}+12.34(I D)^{2} Y P \rho m}\right)=\frac{1.078}{11.50 \times 4.28}\left(23+\sqrt{23^{2}+12.34(4.28)^{2} 30 \times 11.50}\right)=6.64 \mathrm{fps}
$$

- Because VDP $>$ VcDP then the flow that occurs is

Turbulent

- Critical Velocity in Drill pipe annulus (VCanDP) with

Equation (4):

$$
\begin{aligned}
& V c=\frac{1.078}{\rho m(H D-O D)}\left(P V+\sqrt{P V^{2}+9.256(H D-O D)^{2} Y P \rho m}\right)=\frac{1.078}{11.50(12.25-5)}\left(23+\sqrt{\left.23^{2}+9.256(12.25-5)^{2} 30 \times 11.50\right)}\right. \\
& =5.60 \mathrm{fps}
\end{aligned}
$$

Because VanDP $<$ VcanDP then the flow is laminar

The calculation result of mud flow average in Wells "SGT-01" in the example of Depth Interval $2657.48 \mathrm{ft}$ $2723.10 \mathrm{ft}$ (12 1/4 " trajectory) can be seen in Table 4.

Table 4. Results Calculation of Critical Velocity of Mud Flow (Vc) in Example Depth Interval $2657.48 \mathrm{ft}$ - $2723.10 \mathrm{ft} 12$ 1/4 " trajectory.

\begin{tabular}{llll}
\hline \multicolumn{2}{l}{ Critical Velocity in String } & & \\
\hline DP & DC & HWDP & MWD \\
\hline fps & fps & fps & fps \\
\hline 6.64 & 6.88 & 6.91 & 6.88 \\
\hline \multicolumn{5}{l}{ Critical Velocity in Annulus } & & \\
\hline DP & DC & HWDP & MWD \\
\hline fps & fps & fps & fps \\
\hline 5.60 & 5.83 & 5.60 & 5.83 \\
\hline
\end{tabular}

Calculation of Loss of Pressure on Surface Connection (Psc). Calculated by Equation (5), namely:

Data for surface connection:
(Table 1, for combination no 1 )

$$
\begin{gathered}
\text { Psc }=E . \rho^{0.8} \cdot Q^{1.8} \cdot P V^{0.2} \\
\text { Psc }=2.5 \times 10^{-4} \times 11.50^{0.8} \times 659^{1.8} \times 23^{0.2} \\
=391.60 \mathrm{psi}
\end{gathered}
$$

Calculation of Pressure Loss in Drill Pipe (PDP)

- Turbulent flow

- Calculate with Equation (8):

$$
\begin{gathered}
\text { NreDP }=928 \frac{\rho m V D P I D D P}{\mu}=928 \frac{11.50 \times 14.71 \times 4.28}{12.79} \\
=47110.80
\end{gathered}
$$

- The value of $\mathrm{f}$ is obtained from Figure 1 is for DP of 0.003197

- PDP Calculation with Equation (7) 


$$
\mathrm{PDP}=\frac{f \times L \mathrm{DP} \times \rho m \times V \mathrm{DP}^{2}}{(25.8)(I D \mathrm{DP})}=\frac{0.003197 \times 2570.19 \times 11.50 \times 14.71^{2}}{(25.8)(4.28)}=185.38 \mathrm{psi}
$$

Calculation of Pressure Loss in Drill Pipe Annulus (PDP)

- Laminar flow

- Calculate with Equation (6):

$$
\begin{gathered}
P a n D P=\frac{P V \text { LDP VanDP }}{1000(H D-O D D P)^{2}}+\frac{Y P \text { LDP }}{200(H D-O D D P)} \\
\text { PanDP }=\frac{23 \times 2570.19 \times 2.15}{1000(12.25-5.00)^{2}}+\frac{30 \times 2570.19}{200(12.25-5.00)}=55.60 \mathrm{psi}
\end{gathered}
$$

Calculation of Total Pressure Loss in Flow System other than the bit (Total Parasitic Pressure Loss $=P p$ )

$\mathrm{Pp}=\mathrm{Psc}+\mathrm{PDP}+\mathrm{PDC}+\mathrm{PHWDP}+\mathrm{PMWD}+\mathrm{PanDP}+$ PanDC + PanHWDP + PanMWD

$$
\begin{aligned}
= & 391.60+185.38+10+47.43+0.94+55.01+1.19+ \\
& 2.59+0.11 \\
= & 694.85 \mathrm{psi} .
\end{aligned}
$$

\subsubsection{Calculation of Actual Hydraulics Using BHHP \\ Method}

The percentage of pressure loss on the bit compared with the pump pressure on the surface can be known after knowing the magnitude of parasitic pressure loss (Pp).

Calculation of pressure loss on the bit (PB)

$$
\mathrm{PB}=\text { Pdata }-\mathrm{Pp}=1300-694.85=605.15 \mathrm{psi}
$$

Calculate the total optimum nozzle area with Equation (36):

$$
\begin{gathered}
A n=\left[\frac{\mathrm{Pm} \cdot \mathrm{Q}^{2}}{10.858 . \mathrm{Pb}}\right]^{\frac{1}{2}} \\
A n=\left[\frac{11.5 \times 660^{2}}{10.858 \times 605.15}\right]^{\frac{1}{2}}=27.6 \mathrm{in}^{2}
\end{gathered}
$$

Determine the nozzle combination of the nozzle area obtained with Equation (37):

$$
\begin{gathered}
\text { An }=\frac{1}{4} \pi\left(\frac{x}{32}\right)^{2} \times \text { Jumlah Nozzle } \Rightarrow \\
27.6=\frac{1}{4} \times 3.14 \times\left(\frac{x}{32}\right)^{2} \times 4 \\
x=108
\end{gathered}
$$

Calculation of BHHP data using Equation (9) and HPsdata using Equation (10):

$$
\begin{aligned}
& B H H P=\frac{Q \text { data } P b}{1714}=\frac{660 \times 605.15}{1714}=232.67 \mathrm{hp} \\
& H P S=\frac{\text { Qdata } P \text { data }}{1714}=\frac{660 \times 1300}{1714}=499.82 \mathrm{hp}
\end{aligned}
$$

Calculating how much power the bit used to clean the bottom of the wellbore during drilling, by comparing the
BHHP price with the large surface pump power (HPs).

$$
=\frac{B H H P}{H P S} \times 100 \%=\frac{232.67}{499.82} \times 100 \%=46.55 \%
$$

Determine the price Horse Power Per Square Inch (HSI) with Equation (11):

$$
H S I=\frac{B H H P}{\frac{\pi}{4} x(D h)^{2}}=\frac{232.67}{\frac{3.14}{4} \times(12.25)^{2}}=1.97 \mathrm{hp} / \mathrm{in}^{2}
$$

\subsection{Calculation of Actual Cutting Hydraulics}

The calculation steps used to optimize the removal of cutting by drilling mud using the CuttingTransport Ratio (Ft) method, Cutting Concentration (Ca) and Particle Bed Index (PBI) are exemplified in the calculation with Depth Interval $2657.48 \mathrm{ft}-2723.10 \mathrm{ft}$ (trajectory $12 \frac{1}{4}$ " ) are as follows:

Based on the physical properties of drilling mud used, the power law index is calculated by Equation (12):

$$
\begin{gathered}
\mathrm{n}=3.32 \log \left(\frac{2 \mathrm{PV}+\mathrm{YP}}{\mathrm{PV}+\mathrm{YP}}\right) \\
\mathrm{n}=3.32 \log \left(\frac{2 \times 23+30}{23+30}\right) \\
\mathrm{n}=0.52
\end{gathered}
$$

Consistency Index is calculated by using Equation (13):

$$
\begin{gathered}
\mathrm{K}=\frac{(\mathrm{PV}+\mathrm{YP})}{511^{\mathrm{n}}} \\
\mathrm{K}=\frac{510(23+30)}{511^{0.51}} \\
\mathrm{~K}=1057.464
\end{gathered}
$$

Based on mud Rate, Hole Diameter and drill pipe, velocity of mud flow in annulus can be calculated with Equation (14):

$$
\mathrm{Va}=\frac{\mathrm{Q}}{2.45\left(\mathrm{Dh}^{2}-\mathrm{Dp}^{2}\right)}
$$




$$
\begin{gathered}
\mathrm{Va}=\frac{660}{2.45\left(12.25^{2}-5^{2}\right)} \\
\mathrm{Va}=2.15 \mathrm{fps}
\end{gathered}
$$

Calculate critical mud velocity $(\mathrm{Vc})$ for power law fluid with Equation (15):

$$
\begin{aligned}
& \mathrm{Vc}=\left[\frac{3.878 \cdot\left(10^{4}\right) \mathrm{K}}{510 . \rho}\right]^{\frac{1}{2-\mathrm{n}}}\left[\left(\frac{2.4}{\mathrm{dh}-\mathrm{dp}}\right)\left(\frac{2 \mathrm{n}+1}{3 \mathrm{n}}\right)\right]^{\frac{\mathrm{n}}{2-\mathrm{n}}} \\
& \mathrm{Vc}=\left[\frac{3.878 .\left(10^{4}\right) 1057.464}{510 . \mathrm{x} 11.50}\right]^{\frac{1}{2-0.47}}\left[\left(\frac{2.4}{12.25-5}\right)\left(\frac{2 \times 0.51+1}{3 \times 0.51}\right)\right]^{\frac{0.51}{2-0.51}} \mathrm{Vc}= \\
& 377.55 \mathrm{fpm} \\
& \mathrm{Vc}=5.62 \mathrm{fps} \\
& \mu a n=\frac{K}{144}\left(\frac{D H-O D D p}{\text { Van }}\right)^{1-n}\left(\frac{2+1 / n}{0.0208}\right)^{n} \\
& \mu \mathrm{an}=\frac{1057.464}{144}\left(\frac{12.25-5}{2.15}\right)^{1-0.51}\left(\frac{2+1 / 0.51}{0.0208}\right)^{0.51} \\
& \mu \mathrm{an}=139.97 \mathrm{cp}
\end{aligned}
$$

Vertical cutting slip velocity for laminar flow can be calculated with Equation (17):

$$
\begin{gathered}
\mathrm{Vsv}=\frac{82.87 \mathrm{Ds}^{2}(\rho \mathrm{s}-\rho \mathrm{m})}{\mu \mathrm{an}} \\
\mathrm{Vsv}=\frac{82.87 \times 0.16^{2}(19.39-11.50)}{139.97} \\
\mathrm{Vsv}=0.12 \mathrm{fps}
\end{gathered}
$$

Cutting slip velocity after correction of the inclination angle, density, and RPM can be calculated using Equation (18):

$$
\begin{gathered}
\mathrm{Vs}=\left[1+\frac{\theta(600-\mathrm{Rpm})(3+\rho \mathrm{m})}{202500}\right] \mathrm{Vsv} \\
\mathrm{Vs}=\left[1+\frac{0.30(600-30)(3+11.50)}{202500}\right] 0.12 \\
\mathrm{Vs}=0.12 \mathrm{fps}
\end{gathered}
$$

Cutting Transport Ratio (Ft) calculated with Equation (19):

$$
\begin{gathered}
\Phi_{\tau}=\frac{\mathrm{v}_{\alpha}-\mathrm{v}_{\mathrm{S}}}{\mathrm{v}_{\alpha}} \\
\mathrm{Ft}=\frac{2.15-0.121}{2.15} \times 100 \%
\end{gathered}
$$

$$
\mathrm{Ft}=94.51 \%
$$

Cutting Concentration (Ca) calculated with Equation (20):

$$
\begin{gathered}
\mathrm{Ca}=\frac{(\mathrm{ROP}) \mathrm{D}^{2}}{14.7 \mathrm{FtQ}} 100 \% \\
\mathrm{Ca}=\frac{46 \times 12.25^{2}}{14.7 \times 0.9437 \times 659} \times 100 \% \\
\mathrm{Ca}=0.75 \%
\end{gathered}
$$

Particle Bed Index (PBI) can be calculated by first looking for Vsa and Vsr value using Equation (21) and Equation (22):

$$
\begin{aligned}
& -\mathrm{Vsa}=\mathrm{Vs} \cos \varnothing \\
& \mathrm{Vsa}=0.12 \cos 0.30, \\
& \mathrm{Vsa}=0.12 \mathrm{fps} \\
& -\mathrm{Vsr}=\mathrm{Vs} \sin \varnothing \\
& \mathrm{Vsr}=0.12 \sin 0.30 \\
& \mathrm{Vsr}=0.00063 \mathrm{fps}
\end{aligned}
$$

Cutting will settle within a certain time which can be calculated using Equation (23):

$$
\begin{aligned}
\mathrm{T}_{\mathrm{S}} & =\frac{\frac{1}{12}(\mathrm{Dh}-\mathrm{Dp})}{\mathrm{v}_{\mathrm{Sr}}} \\
\mathrm{TsDP} & =\frac{1 / 12(12.25-5)}{0.00063} \\
\mathrm{Ts} & =953.02 \mathrm{sec} .
\end{aligned}
$$

The distance was taken by cutting before settling can be calculated using Equation (24):

$$
\begin{gathered}
\mathrm{L}_{\mathrm{cDP}}=\left(\mathrm{v}_{\mathrm{a}}-\mathrm{v}_{\mathrm{sa}}\right) \mathrm{T}_{\mathrm{S}} \\
\mathrm{Lc}=(2.15-0.121) \times 953.02 \\
\mathrm{Lc}=1934.53 \mathrm{ft} .
\end{gathered}
$$

Particle Bed Index (PBI ) calculated with Equation (25):

$$
\mathrm{PBI}=\frac{\frac{1}{12}(\mathrm{Dh}-\mathrm{Dp})\left(\mathrm{v}_{\mathrm{a}}-\mathrm{v}_{\mathrm{sa}}\right)}{\mathrm{L}_{\mathrm{c}} \mathrm{v}_{\mathrm{sr}}} \quad \mathrm{PBI}=\frac{\left.\frac{1}{12}(12.25-5)(2.15-0.121)\right)}{(1934.535) \times(0.00063)}
$$

PBI $=1$

The results of the actual drilling powder lift calculations exemplified at the $2657.48 \mathrm{ft}-2723.10 \mathrm{ft}$ (12 $1 / 4$ " trajectory) depth can be seen in Table 5 .

Table 5. Actual Cutting Lift Result on Wells "SGT-01" in Example Depth Interval $2657.48 \mathrm{ft}-2723.10 \mathrm{ft}$ (trajectory 121/4").

\begin{tabular}{llllll}
\hline \multirow{2}{*}{ Depth Interval (ft) } & \multirow{2}{*}{ Dh === (in) } & \multirow{2}{*}{ Q Gpm } & \multicolumn{4}{l}{ Drill Pipe } \\
\cline { 4 - 6 } & & & $\mathbf{F t}$ & $\mathbf{C a}$ & PBI \\
\cline { 4 - 6 } & & $\mathbf{\%}$ & $\mathbf{\%}$ & $\mathbf{\%}$ \\
\hline $2657.48-2723.10$ & 12.25 & 660 & 94.51 & 0.75 & 1 \\
\hline
\end{tabular}

Furthermore, ROP, BHHP, and \% BHHP / HHP are 
evaluated on the actual condition. The evaluation results of ROP, BHHP, \% BHHP / HHP at each depth interval can be seen in Table 6.

Table 6. Evaluation Results\% BHHP / HPs, ROP and BHHP Wells "SGT-01" at Each Depth Interval (trajectory 12 1/4").

\begin{tabular}{llll}
\hline \multirow{2}{*}{ Depth Interval } & Actual & & \\
\cline { 2 - 4 } & BHHP/HPs & ROP & BHHP \\
\hline $\mathbf{f t}$ & $\mathbf{\%}$ & $\mathbf{f t} / \mathbf{h r}$ & $\mathbf{h p}$ \\
\hline $909.55-1072.83$ & 43.34 & 48.72 & 248.31 \\
$1072.83-1099.88$ & 47.45 & 59.33 & 309.64 \\
$1099.88-1245.18$ & 42.30 & 42.76 & 229.66 \\
$1245.18-1393.93$ & 46.94 & 55.69 & 305.36 \\
$1393.93-1524.68$ & 42.21 & 40.87 & 219.95 \\
$1524.68-1787.87$ & 43.25 & 44.39 & 224.57 \\
$1787.87-1830.70$ & 49.09 & 79.24 & 362.48 \\
$1830.70-2375.32$ & 54.72 & 94.98 & 455.81 \\
$2375.32-2657.48$ & 63.01 & 128.45 & 631.42 \\
$2657.48-2723.10$ & 46.55 & 46 & 232.67 \\
\hline
\end{tabular}

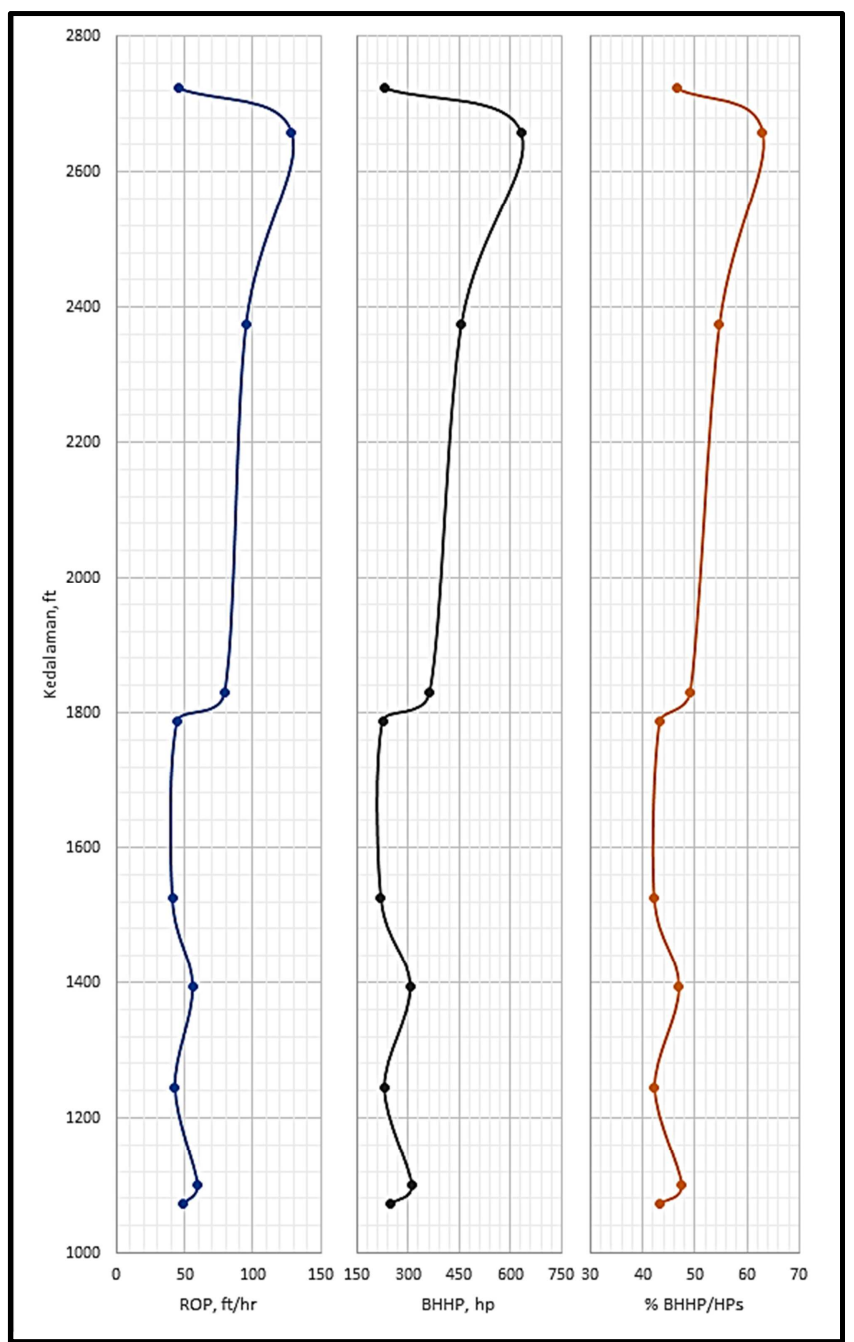

Figure 3. Graph Evaluation Depth vs ROP, BHHP and\% BHHP Wells "SGT-01" on Each Depth Interval (trajectory 12 1/4").

Based on the evaluation of $\%$ BHHP / HPs, ROP and BHHP at the depth of $909.55 \mathrm{ft}-2723.10 \mathrm{ft}$ shown in Table 6 found the price of $\%$ BHHP / Hps less optimum, where \% BHHP / HPs condition is still below $65 \%$ aims to raise the price of $\%$ BHHP
/ HPs. BHHP value is closely related to ROP value, where if BHHP value is small then ROP is also small otherwise if BHHP is big value then ROP is also big value, it is illustrated in (Figure 3). Basically one of the purposes of this research is to raise the ROP, if the ROP is high then the target drilling time can be achieved well.

\subsection{Calculation of Pump Rate and Pump Pressure}

DATA:

- Pump Data

Type / Model: PZ-9 (PZ) / Duplex

Number of Units: 3

Liner Diameter: 6.5 in

Stroke Per Minute: 101.5

Qmax: 504 gpm

Hpmax / Pumps: 1000 hp

Discharge Pressure: 3400.79 psi

Efficiency: $87 \%$

\subsubsection{Calculating Qmax Pump}

Calculation of the maximum pump Rate from the combined three pumps, namely the duplex pumps arranged in parallel as follows:

Calculate maximum pump power (HPmax):

HPmax $=$ HP pump max $\times$ Eff pump $\times$ Number of Pumps

$$
\begin{gathered}
H P \max =1000 \times 0.87 \times 3 \\
H P \max =2610 \mathrm{hp}
\end{gathered}
$$

Calculating the maximum pump rate (Qmax):

Qmax $=$ Number of Pumps $\times$ Qmax pump $\times$ Eff pump

$$
\begin{gathered}
\text { Qmax }=3 \times 504 \times 0.87 \\
\mathrm{Qmax}^{=} 1315.12 \mathrm{gpm}
\end{gathered}
$$

- Calculate pump maximum pressure (Pmax) using Equation (26):

$$
\begin{gathered}
P \max =\frac{H P \max \times 1714}{Q \max } \\
P \max =\frac{2610 \times 1714}{1315.12}=3400.79 \text { psi }
\end{gathered}
$$

\subsubsection{Calculate Qmin Pump}

Qmin is calculated using the Minimum Annular Velocity Concept in the annulus.

Calculate Cutting Concentration with Equation (34):

$$
\begin{aligned}
\text { Cconc } & =0.01778 \text { ROP }+0.505 \\
& =0.01778(46)+0.505 \\
& =1.32 \%
\end{aligned}
$$

Calculate cutting velocity (Vcut) with Equation (33): 


$$
\begin{aligned}
& \text { Vcut }=\frac{R O P}{36\left[1-\left[\frac{O D}{D H}\right]^{2}\right] \text { Cconc }} \\
& \begin{aligned}
& \text { Vcut }= \frac{46}{36\left[1-\left[\frac{5}{12.25}\right]^{2}\right] 1.32} \\
& \text { Vcut }=1.15 \mathrm{fps}
\end{aligned}
\end{aligned}
$$

Minimum Velocity, with Equation (31):

$$
\begin{gathered}
\text { Vmin }=\text { Vcut }+\mathrm{Vs} \Theta \leq 45 \\
\text { Vmin }=\text { Vcut }+\left[+\frac{\theta(600-R p m)(3+\rho m)}{202500}\right] V s v \\
\text { Vmin }=1.15+\left[1+\frac{0.30(600-20)(3+11.50)}{202500}\right] 0.12 \\
\text { Vmin }=1.27 \mathrm{fps}
\end{gathered}
$$

Minimum mud Rate in annulus with Equation (35):

$$
\begin{gathered}
\text { Qmin }=\frac{1}{4} \pi\left(d h^{2}-o d^{2}\right) \times V \min \times 3.1172 \\
\text { Qmin }=\frac{1}{4} 3.14\left(12.25^{2}-5^{2}\right) \times 1.27 \times 3.1172 \\
\text { Qmin }=390.79 \text { gpm. }
\end{gathered}
$$

The results of Minimum Annular Velocity calculations at the "SGT-01" Wells at the $2657.48 \mathrm{ft}-2723.10 \mathrm{ft}(12 \times 12 \mathrm{~cm})$ Depth Interval can be seen in Table 7.

Table 7. Results of Annular Velocity Minimum Calculation at Wells "SGT-01" in Example Interval Interval Depth $2657.48 \mathrm{ft}$ - $2723.10 \mathrm{ft}$ Trajectory 121/4".

\begin{tabular}{lllll}
\hline Interval & Cconc & Vcut & Vmin & Qmin \\
\hline $\mathbf{f t}$ & $\%$ & fps & fps & gpm \\
\hline $2657.48-2723.10$ & 1.32 & 1.15 & 1.27 & 390.79 \\
\hline
\end{tabular}

\subsection{Optimization of Hydraulics and Cutting}

DATA:

Depth Interval $=2657.48 \mathrm{ft}-2723.10 \mathrm{ft}$

$\mathrm{Q}$ actual $=660 \mathrm{gpm}$

$\mathrm{P}$ actual $=1300 \mathrm{psi}$

Pmax $=3400.79$ psi

Hp pump $=1000 \mathrm{hp}$

pm $=11.5 \mathrm{ppg}$

$\mathrm{HD}=12.25$ in

\subsubsection{Hydraulic Bit Optimization}

Optimization is done by trial and error by raising the Rate

\begin{tabular}{|c|c|c|c|c|c|}
\hline Depth & $\mathbf{Q}$ & Ppump & ВННР & HPs & BHHP/HPs \\
\hline (ft) & gpm & psi & (HP) & (HP) & $\%$ \\
\hline $2657.48-2723.10$ & 660 & 1300 & 232.39 & 500.58 & 46.42 \\
\hline $2657.48-2723.10$ & 670 & 1520 & 314.76 & 594.17 & 52.98 \\
\hline $2657.48-2723.10$ & 680 & 1740 & 399.39 & 690.32 & 57.86 \\
\hline $2657.48-2723.10$ & 690 & 1960 & 486.28 & 789.03 & 61.63 \\
\hline $2657.48-2723.10$ & 710 & 2260 & 608.81 & 936.17 & 65.03 \\
\hline HSI & \multicolumn{5}{|c|}{ Nozzle } \\
\hline hp/in ${ }^{2}$ & \multicolumn{5}{|c|}{ 1/32in' } \\
\hline 1.972733 & \multicolumn{5}{|c|}{$27 \times 27 \times 277 \times 27$} \\
\hline 2.672018 & \multicolumn{5}{|c|}{$22 \times 22 \times 22 \times 22$} \\
\hline 3.390471 & \multicolumn{5}{|c|}{$21 \times 21 \times 21 \times 21$} \\
\hline 4.128058 & \multicolumn{5}{|c|}{$20 \times 20 \times 21 \times 21$} \\
\hline 5.16819 & \multicolumn{5}{|c|}{$19 \times 19 \times 20 \times 20$} \\
\hline
\end{tabular}
parameter and pump pressure, but in trial and error also must pay attention to the efficiency of each pump's ability to be used optimally. On bit hydraulic optimization and removal of "SGT-01" wells with a depth interval of $2657.48 \mathrm{ft}-2723.10 \mathrm{ft}$. Pumps are arranged in parallel. Results of trial and error optimization of bit hydraulic well "SGT-01" can be seen in Table 8.
Table 8. Results Trial and Error Optimization Hydraulics Bit at Wells "SGT-01" in Interval example.

After BHHP optimization, it is possible to predict the increase of ROP by extrapolation, the result of the predicted increase of ROP after BHHP optimization. The predicted increase of ROP can be illustrated in (Figure 4) where the trendline in actual condition and optimization shows the change of ROP value after BHHP is optimized.

Extrapolation of ROP vs BHHP is obtained from the trendline on the graph, that is:

$$
\begin{aligned}
& y=0.2149 X-5.1672 \\
& y=(0.2149 \times 650)-5.1672 \\
& y=134.51 \mathrm{fph}
\end{aligned}
$$

Basically, in conducting an evaluation of mud hydraulics and removal of cutting, WOB and RPM parameters are also related to BHHP, but in this paper, the authors focus on the evaluation and optimization of hydrolysis that is by predicting the increase of ROP because in this case study WOB and RPM parameters considered optimum.

At (Figure 4) it can be concluded that the predicted increase of ROP is obtained by extrapolating linearly, so that ROP value will be reached up to the optimum condition that is $65 \%$ BHHP / HPs, where after passing the restriction then ROP will decrease so that regrinding occurs (reforestation) and bit bailing.

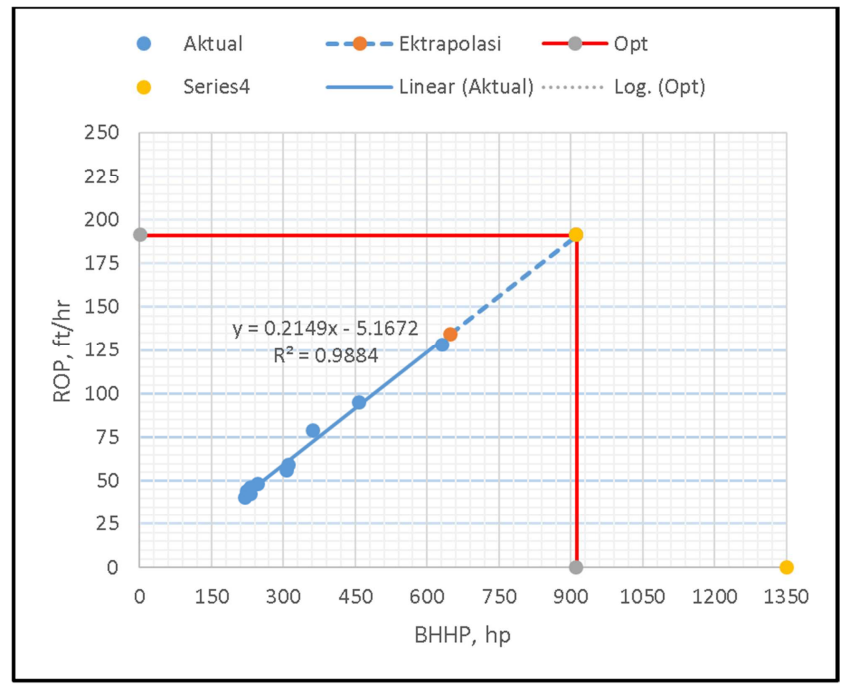

Figure 4. Relationship of ROP vs. BHHP Wells "SGT-01" on actual condition and optimization. 


\subsubsection{Optimization of Cutting Apparel}

Furthermore done trial and error optimization of cutting appointment, in optimizing cutting appointment, there are some parameters that influence to reach the optimum result.
Some of the parameters that influence the optimization of cutting appointment are Rate $(\mathrm{Q})$, pump pressure $(\mathrm{P})$ and rate of penetration (ROP). Results of trial and error optimization of cutting wells "SGT-01" can be seen in Table 9.

Table 9. Trial and Error Outputs Cutting Lifting in Wells "SGT-01" in the example depth interval $2657.48 \mathrm{ft}-2723.10 \mathrm{ft} 121 / 4$ " trajectory.

\begin{tabular}{llllll}
\hline Depth & Q & Ppump & ROP & Ft & Ca \\
\hline (ft) & gpm & psi & ft/h & \% & \% \\
\hline $2657.48-2723.10$ & 660 & 1300 & 46 & 94.37504 & 0.753896 \\
$2657.48-2723.10$ & 670 & 1520 & 62.4 & 94.41883 & 1.008156 \\
$2657.48-2723.10$ & 680 & 1740 & 80.6 & 94.46164 & 1.281926 \\
$2657.48-2723.10$ & 690 & 1960 & 99.3 & 94.5035 & 1 \\
$2657.48-2723.10$ & 710 & 2260 & 125.6 & 94.58452 & 1.555101 \\
\hline
\end{tabular}

\section{Discussion}

Evaluation of bit hydraulics and removal of cutting at vertical drilling operations in the example of depth interval $2657.48 \mathrm{ft}-2723.10 \mathrm{ft}$ (trajectory $121 / 4$ ") Wells" SGT-01" "Tranusa" field, obtained bit hydraulics under actual conditions for $2657.48 \mathrm{ft}-2723.10 \mathrm{ft}$ obtained Bit Hydraulic Horse Power (BHHP) of $232.67 \mathrm{hp}$, Hors Power Surface (HPs) of $499.82 \mathrm{hp}$, Horse Power per Square Inches (HSI) of $1.67 \mathrm{hp}$ $/ \mathrm{in}^{2}$ and percentage (BHHP / HPs) of $46.55 \%$ ( $<65 \%$ which indicates less optimum then optimized hydraulic bit circulation rate optimized to $710 \mathrm{gpm}$ and pump pressure 2260 psi with 19x19x20x20 in nozzle size, resulting Bit Hydraulic Horse Power (BHHP) of $606.81 \mathrm{hp}$, Horse Power Surface (HPs) $936.47 \mathrm{hp}$, Horse Power per Square Inches (HSI) of 5.4 hp / in ${ }^{2}$ and percentage (BHHP / HPs) of $65 \%$ (optimum). Evaluation of cutting cut on actual condition for depth interval $2657.48 \mathrm{ft}-2723.10 \mathrm{ft}$ with Rate (Q) $660 \mathrm{gpm}$, pump pressure 1300 psi resulted Cutting Transport Ratio (Ft) $94.51 \%$ (> $90 \%$ ), optimum. Cutting Concentration $(\mathrm{Ca})$ of $0.75 \%$ and Particle Bed Index (PBI) of 1, which indicates no precipitation of cutting is subsequently carried out. Optimization of cutting in annulus obtained Cutting Transport Ratio $(\mathrm{Ft})$ changed from $94.51 \%$ to $94.58 \%$ Cutting Concentration $(\mathrm{Ca})$ the increase from $0.75 \%$ to $1.9 \%$ and the Particle Bed Index (PBI) remains 1 . Changes that occur are still within the maximum conditions, so as not to change the optimum conditions of cutting appointment. The calculation result using the minimum annular velocity concept gives the minimum discharge rate $(\mathrm{Q})$ rate allowed by agra of drill powder to be lifted to the surface is $390 \mathrm{gpm}$, the maximum Rate $(\mathrm{Q})$ given to the pump is $1315.12 \mathrm{gpm}$ and yields an optimum rate of 710 $\mathrm{gpm}$. The final result of the evaluation and optimization of bit hydraulics and the removal of cutting is predicted to increase ROP from 46 fph to $125.66 \mathrm{fph}$, thus it is expected to be a record in the next drill.

\section{Conclusion}

Based on the evaluation of hydraulic removal of cutting and bit hydraulics on vertical drilling operation in the example of depth interval $2657.48 \mathrm{ft}-2723.10 \mathrm{ft}$ (trajectory $121 / 4$ "). Wells "SGT-01" field "Tranusa", it can be concluded as follows:
1. Hydraulic Horse Power (BHHP) evaluation of 232.67 hp, Horse Power Surface (HPs) of $499.82 \mathrm{hp}$, Horse Power per Square Inches (HSI) of $1.67 \mathrm{hp} / \mathrm{in}^{2}$ and percentage (BHHP / HPs) amounted to $46.55 \%(<65 \%)$.

2. Based on the above evaluation indicates less optimal bit hydraulics so that the drilling rate is not achieved properly.

3. Evaluation of cutting lift at the actual condition with Rate (Q) 660 gpm, pump pressure 1300 psi result Cutting Transport Ratio (Ft) equal to $94.51 \%$ (> 90\%), is optimum. Cutting Concentration (Ca) of $1.61 \%$ and Particle Bed Index (PBI) of 1, indicating no cutting deposition.

4. Optimization of bit speed hydraulics is optimized to 710

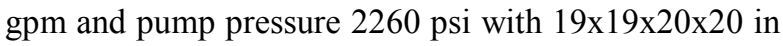
nozzle size, resulting Bit Hydraulic Horse Power (BHHP) of $606.81 \mathrm{hp}$, Horse Power Surface (HPs) $936.47 \mathrm{hp}$, Horse Power per Square Inches (HSI ) of 5.4 $\mathrm{hp} / \mathrm{in}^{2}$ and percentage (BHHP / HPs) of $65 \%$ (optimum).

5. Cutting Transport Ratio (Ft) was changed from $94.51 \%$ to $94.58 \%$ Cutting Concentration $(\mathrm{Ca})$ increased from $0.75 \%$ to $1.9 \%$ and Particle Bed Index (PBI) remained 1 . Changes were still within the limit the maximum conditions, so as not to change the optimum conditions of cutting appointment.

6. The calculation result using the minimum annular velocity concept gives the minimum allowable rate of discharge rate $(\mathrm{Q})$ so that the drilling powder can be lifted to the surface is $390 \mathrm{gpm}$, the maximum Rate (Q) given to the pump is $1315.12 \mathrm{gpm}$ and yields an optimum Rate of $710 \mathrm{gpm}$.

7. The final result of the evaluation and optimization of bit hydraulics and the removal of cutting is predicted to increase the ROP from 46 fph to $125.66 \mathrm{fph}$, thus it is expected to be the record at the next drilling.

\section{References}

[1] Saleem. Q. T,. A. H. Tunio, N. A. Ghirano and S. Irawan, 2011. Is It Possible to Ignore Problems Rising During Vertical Drilling A. Review. Res. J. Appl. Sci. Eng. Technol., 3 (11): 1331-1336. 
[2] T. Eren and M. E. Ozbayoglu. Real time optimization of drilling parameters during drilling operations. In SPE Oil and Gas India Conference and Exhibition, 2010, SPE-129126, 2010 .

[3] F. E. Beck, Arco Alaska, Inc., and J. W. Powelland MarioZamora, The Effect of Rheology on Rate of Penetration SPE/1ADC Drilling Conference held In Amsterdam, 28 February-2 March 1995.

[4] A. M. Palaman, M. K. Ghassem Al-Askari, B. Salmani, B. D. Al-Anazi and M. Masihi, "Effect of Drilling Fluid Properties on Rate of Penetration", Scientic Original Paper, 2009.

[5] Moses, A. A. and F. Engbon, 2011. Semi-analyical models on the effect of drilling fluid properties on Rate of Penetration (ROP), SPE no. 150806. Proceedings of the Nigeria Annual International Conference and Exhibition, 30 July-3, Abuja, Nigeria.

[6] Bourgoyne, A. T., et al. (1986), "Applied Drilling Engineering”, Society of Drilling Engineerings, Richardson, Texas.

[7] Gatlin, C. (1960), "Petroleum Engineering Drilling and Well Completion", Prentice Hall Inc., Englewood Clift, New Jersey.

[8] Lummus. J. L. (1986), Drilling Fluids Optimization”, Penn Well Publishing Co., Tulsa Oklahoma.
[9] Millpark Staff (1993), "Drilling Fluid Manual”, Millaprk Drilling Fluids, A Baker Hughes Company.

[10] Preston L. Moore (1974)., "Drilling Practices Manual", The Petroleum Publishing Co., Tulsa.

[11] Rabia, H. (1985), "Oil Well Drilling Engineering Principles and Practice", University of New Castle, UK.

[12] Rudi Rubiandini R. S "Diklat Kuliah Teknik dan Alat Pemboran".

[13] T. I. Larsen, A. A. Pilehvari, and J. J. Azar (1997), SPE Paper "Development of a New Cutting Transport Model for High-Angle Wellbores Including Horizontal Well", SPE No 25872 .

[14] Ziedler. H. Udo, Dr. P. E. (1988), "Drilling Fluid Technology applied to Horisontal Drilling", Maurer Engineering Inc, Houston, Texas.

[15] Herianto. Dkk (2001) Optimisasi Hidrolika Pada Penggunaan Down Hole Mud Motor (DHMM) dengan Konsep Minimum Annular Velocity untuk Pemboran Sumur-Sumur Berarah.

[16] Norton J Lapeyrouse, "Formulas and Calculations for Drilling, Production and Workover, Second Edition". 